\title{
DUAL HEAT TREAT PROCESS DEVELOPMENT FOR ADVANCED DISK APPLICATIONS
}

\author{
David P. Mourer, GE Aircraft Engines, Lynn, MA \\ Jeffrey L. Williams, GE Aircraft Engines, Cincinnati, OH
}

Keywords: Powder Metal René 104, Heat Treat

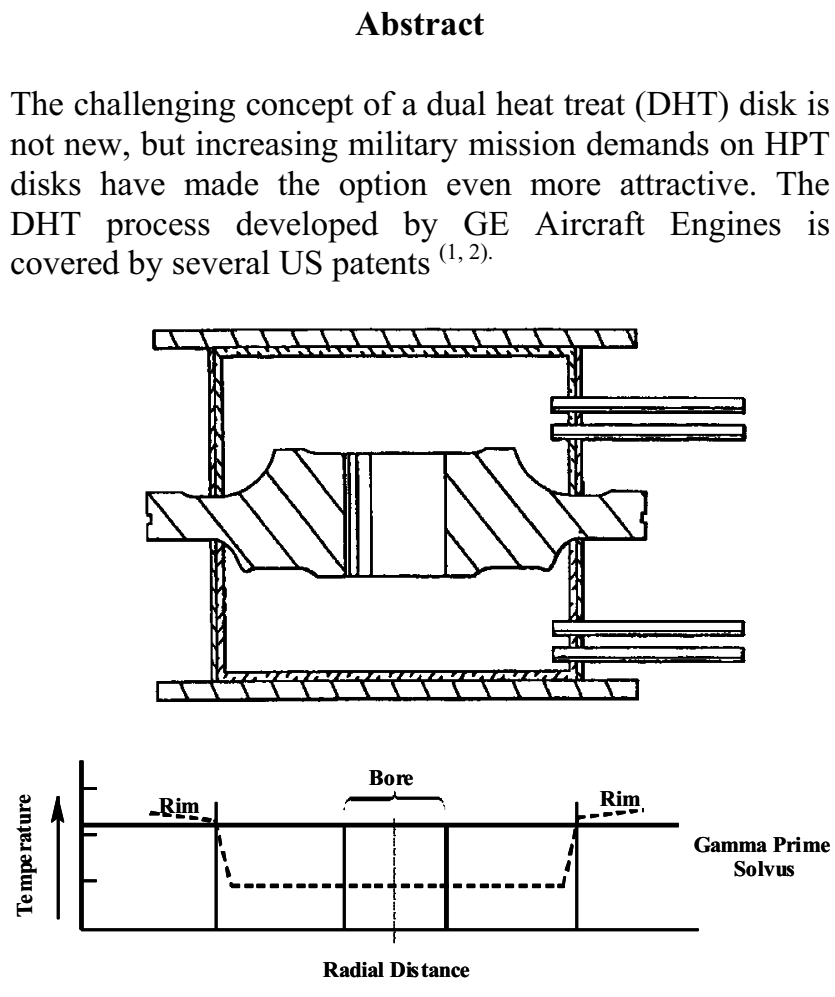

Figure 1. Schematic of dual heat treat fixture and work piece thermal gradient

The process was developed and demonstrated at a current aerospace forging supplier, thus opening the technology and associated benefits to the industry as a whole. The alloy selected was Alloy René 104, an extruded + isothermally-forged Ni-base powder alloy originally developed under NASA-EPM funding (3). This paper reviews the success of the DHT process development in terms of thermal process variability and the resultant microstructures achieved.

\section{Background}

The Navy and GEAE funded Dual-Use Science \& Technology program "Cost-Effective Fabrication Processes for Advanced Superalloy Disks" was a taskoriented, three-phase approach to procure material, and develop a dual heat treat (DHT) manufacturing practice to yield a fine, high-strength bore and a coarse, damagetolerant rim using GEAE's René 104 alloy in an advanced disk shape.

Process development, including thermo-coupled disk trials and finite-element modeling of the thermal response of the forgings, was performed to manufacture DHT articles for evaluation. Destructive evaluation of three disk forgings was used to establish the bore, rim and transition zone grain sizes to define the capability of the DHT process.

\section{Full Scale Material Procurement}

Full-scale $235 \mathrm{~mm}$ diameter billet of René 104 was procured for the manufacture of the full-scale advanced military demonstrator engine HPT disk forgings for DHT in the final phase of the program. Billet from two extrusions was utilized to enable a broader evaluation of process variability by incorporating two heats of material in the program.
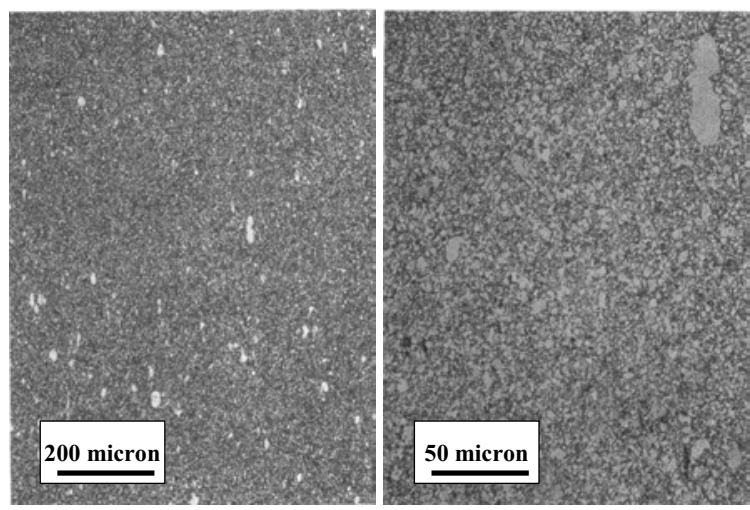

Figure 2. Microstructure of extrusions used for DHT disk forgings.

The required powder material was atomized, extruded and inspected by Wyman Gordon (Brighton, MI) and met all chemical $^{(4)}$, microstructural and quality requirements. The material was then sectioned into mults sized for forging 
into an advanced disk shape. Forging mults were approximately $230 \mathrm{Kg}$ in weight and $610 \mathrm{~mm}$ in diameter.

\begin{tabular}{|c|l|l|l|l|l|l|l|l|l|}
\hline Alloy Wt\% & Co & Cr & Mo & W & Nb & Al & Ti & Ta & C \\
\hline \multirow{2}{*}{ R104 $^{(5)}$} & 14 & $11-$ & 2.7 & $0.5-$ & 0.25 & & & 0.5 & 0.015 \\
& 23 & 15 & 5 & 3 & -3 & $2-5$ & $3-6$ & 4 & 0.1 \\
\hline $\begin{array}{l}\text { AsHIP } \\
\text { R95 }{ }^{(6)}\end{array}$ & 8 & 13 & 3.5 & 3.5 & 3.5 & 3.5 & 2.5 & & 0.06 \\
\hline R88 $^{(6)}$ & 13 & 16 & 4 & 4 & 0.7 & 2.2 & 3.8 & na & 0.05 \\
\hline
\end{tabular}

Figure 3 Nominal compositions are provided for reference.

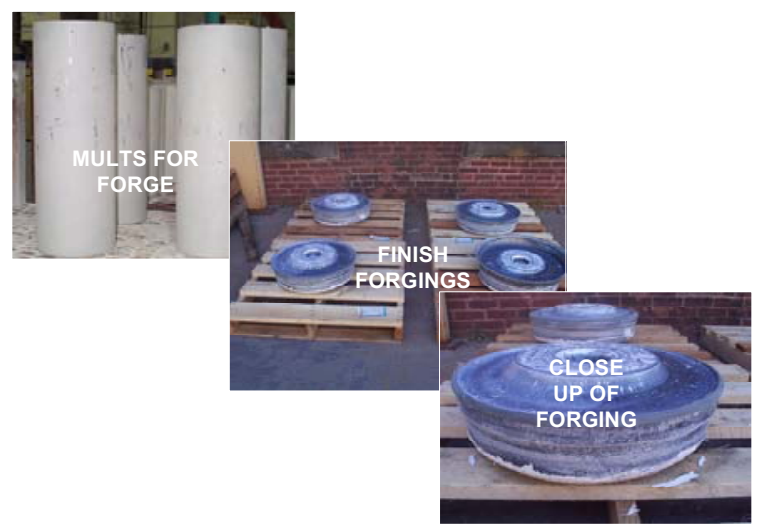

Figure 4. View of mults prior to forging, the four completed forgings and a close up of a typical forging.

Wyman Gordon (Worcester, MA) isothermally forged the four René 104 mults for the DHT demonstration trials. All four forgings were made without incident per the defined deformation schedule.

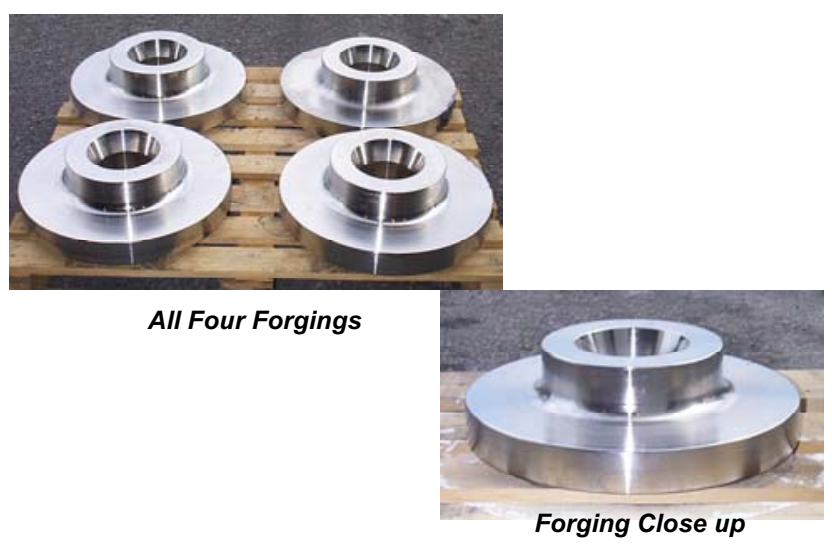

Figure 5. View of the René 104 forgings for DHT after ultrasonic inspection and machined to the final DHT shape.

The forgings were machined to a sonic/heat treat shape without incident and inspected to current production criteria. Inspection revealed no sonic indications or unusual noise.

Based on experience with the delayed fan + oil quench process planned for the DHT shape, Wyman Gordon (Houston, TX) defined the details of the proposed heat treat shape. This contour was also used for machining of the René 104 DHT shapes for evaluation. A schematic cross-section of the shape contours used for DHT trials is shown in Figure 6.

\section{Dual Heat Treat Process Development}

The overall plan consisted of several key steps 1) Define the target product and process metrics based on component needs and material response, 2) Perform iterative, integrated processing and modeling trials to finalize a DHT practice, 3) Perform an initial full scale René 104 DHT trial and selected critical evaluations, and finally 4) DHT the remaining René 104 disks based on success of the initial DHT trial.

Over 35 thermo-coupled DHT processing trials were performed and used to refine the DHT fixture design as well as develop the required process procedures and control parameters. This work included proprietary furnace modifications as well as geometry modifications to the work piece to achieve the process metrics. Parallel finite element modeling was performed to guide and confirm process development. Cooling rate predictions were performed and utilized to establish an acceptable practice consistent with prior experience.

Based on advanced disk requirements for the transition zone location and geometry constraints imposed by the forgings, Wyman Gordon defined the disk shape for the heat treat trials including the thermocouple locations and associated instrumentation details.

Wyman-Gordon modeled the thermocouple placement pattern using finite-element methods. The layout of thermocouple locations for the initial shape is shown in Figure 6 . The thermocouple disk shape was manufactured from IN718 alloy allowing all the René 104 forge shapes to be processed to the optimized DHT process. This shape with the thermocouple locations as shown was used for the DHT trials. 


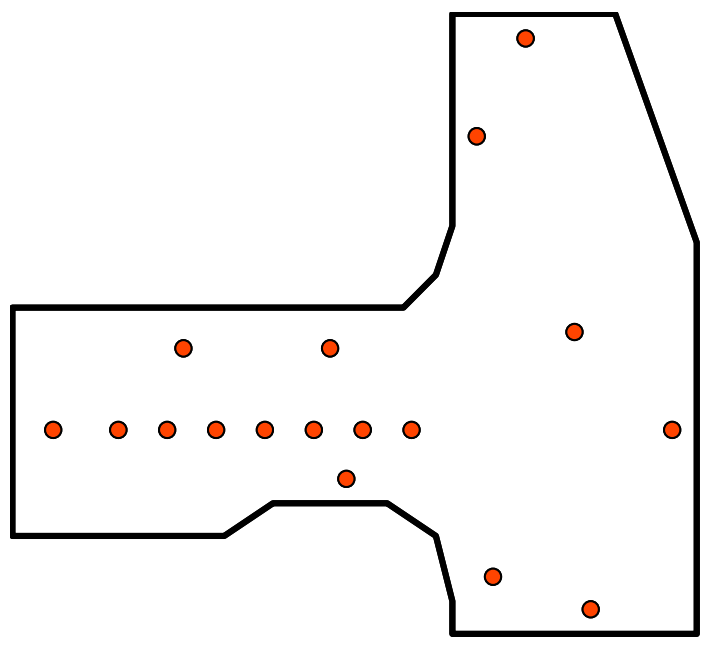

Figure 6. Schematic of thermocouple locations superimposed on the initial advanced disk DHT disk shape.

The trials used an active air cooling fixture to control the trans-solvus gradient. Initial trials achieved the desired gradient from subsolvus to supersolvus temperatures in the web region, but the initial circumferential temperature variation was larger than anticipated. Variation in temperature obtained from comparing rim/web thermocouples located $180^{\circ}$ apart with similar radial locations ranged up to approximately $17^{\circ} \mathrm{C}$. Several factors were evaluated to achieve the desired improvements in circumferential temperature uniformity.

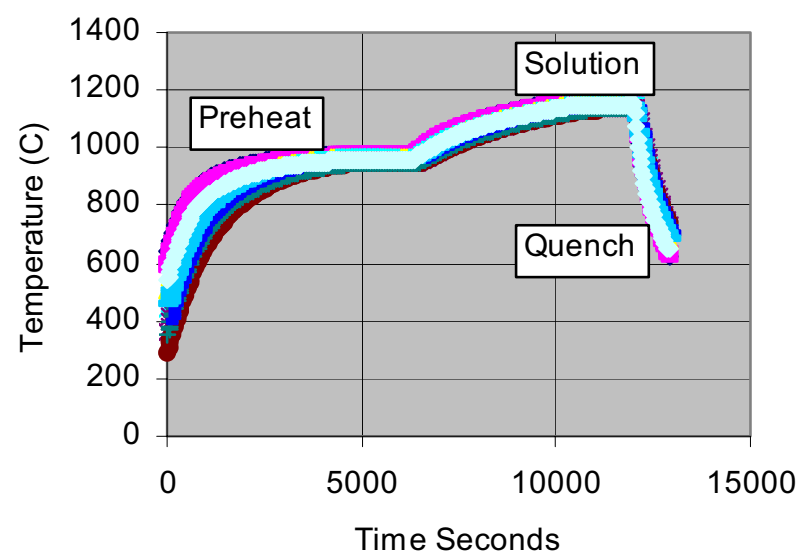

Figure 7. Typical thermocouple data output for DHT processing cycle from an early DHT trial.

Based on the results obtained from the early trials, a final fixture configuration was designed. This fixture included modification of the cooling air exhaust, thought to be a significant factor in the furnace heating uniformity and circumferential variability in the rim/web metal temperatures. A goal of the final trials was to gather sufficient thermal data to allow inverse heat transfer analysis to derive the heat transfer coefficients (HTC). Definition of HTC's allowed finite element heat treat modeling of geometry and process options in parallel with the actual heat-treat trials. Typical data and comparison with modeling predictions is shown in Figure 8.

A comparison of circumferential symmetry is shown in Figure 9. The variation was determined to be within experience and suitable for commitment of the René 104 forgings to DHT processing. For the DHT portion of the cycle, shown in Figure 10, predicted temperatures were within $11^{\circ} \mathrm{C}$ of measured values, which was considered excellent agreement.

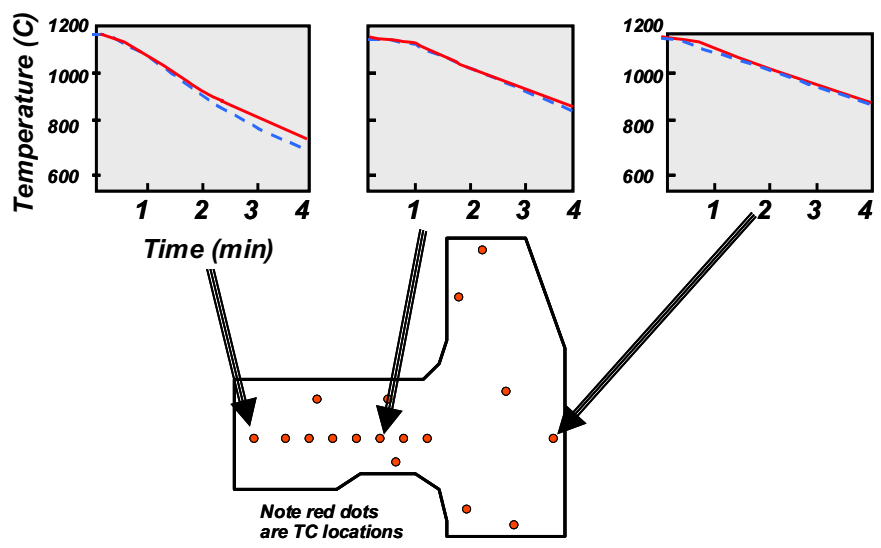

Figure 8. Schematic of finite element modeling cooling rate-modeling predictions. Modeling predictions are shown as dotted red lines with TC data as solid blue lines.

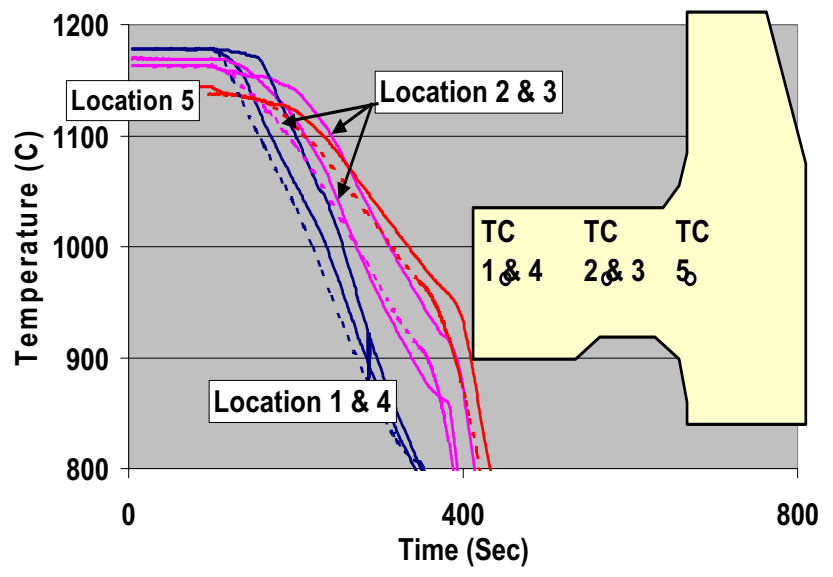

Figure 9. DHT trial run temperature versus time data to assess circumferential variations in temperature. 


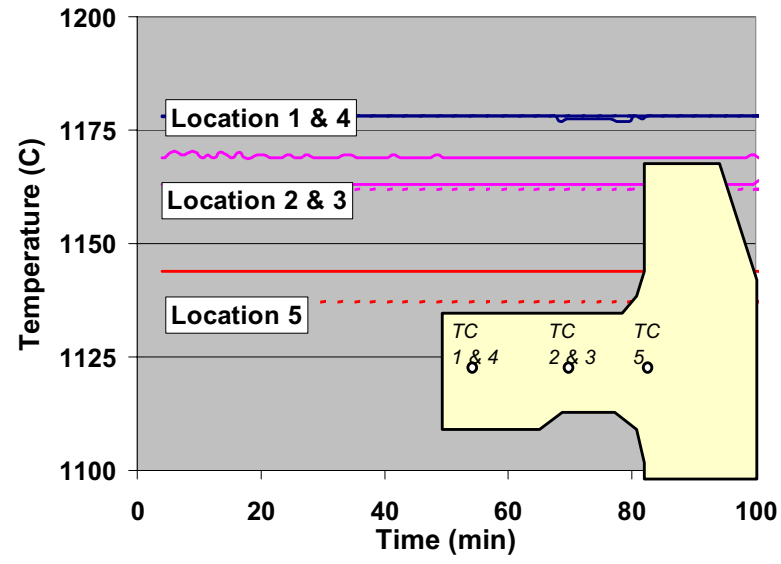

Figure 10. Solution cycle portion of dual heat-treat thermocouple data versus model predictions (dotted lines). Excellent agreement is shown.

\section{Dual Heat Treat Quench Process Modeling Activity}

Cooling rate profiles were generated from the heat treat process model and are shown in Figure 11. These data were used to confirm the selection of the variables controlling the quench process. The $1093-871^{\circ} \mathrm{C}$ cooling rates from both the bore $\left(60-80^{\circ} \mathrm{C} /\right.$ minute $)$ and the rim $\left(70-110^{\circ} \mathrm{C} /\right.$ minute $)$ were within typical production experience and were judged suitable to achieve the desired microstructures.

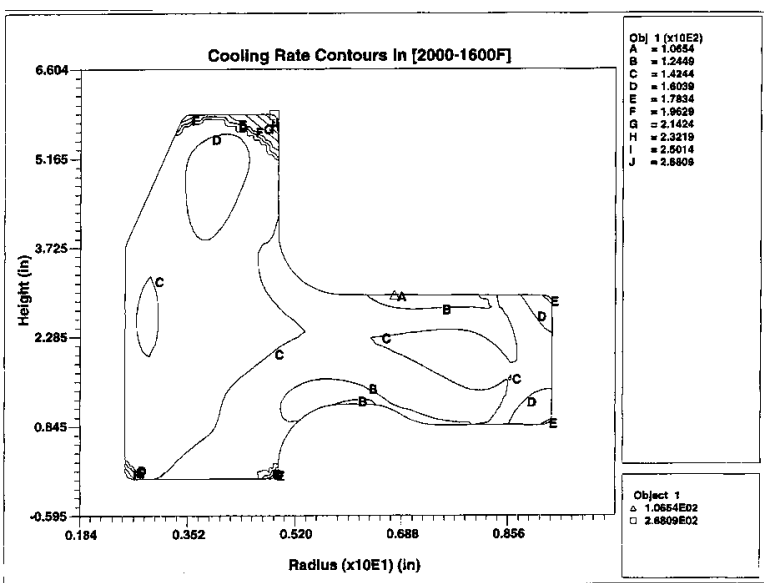

Figure 11. Finite element modeling cooling rate predictions $\left({ }^{\circ} \mathrm{F} /\right.$ minute) for the overall dual heat quench.

In addition to the cooling rate predictions, finite element modeling was used to predict residual stresses in both the DHT disk and a baseline case of a uniform temperature supersolvus disk of the same shape. Full cross-sectional predictions were made to yield the summary predictions for maximum values of each stress component.
René 104 residual stress predictions were compared to pre-existing data on the same shape in a current alloy (René 88DT) and are shown in Figure 12. Both the baseline supersolvus and DHT processes for René 104 are predicted to provide lower residual stresses relative to current René 88DT practices, with the DHT version providing the lowest residual stresses. Therefore, René 104 provides a desirable reduction in residual stress, which results in minimized machining distortion and growth of disks in operation.

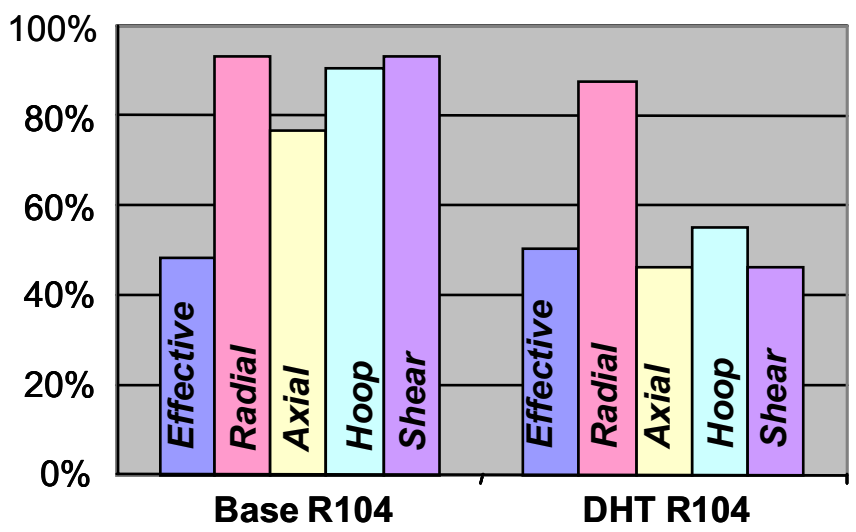

Figure 12. Finite element model predictions for residual stresses comparing baseline supersolvus René 104 versus DHT René 104. The scale is comparative to René 88DT in the same shape $(100 \%=100 \%$ of the René 88DT value).

\section{Dual heat treat demonstration trials}

Based on the level of success demonstrated in the dual heat treat trials using the instrumented surrogate disk and the success in finite element modeling of the process, the first René 104 forging was committed to DHT processing.

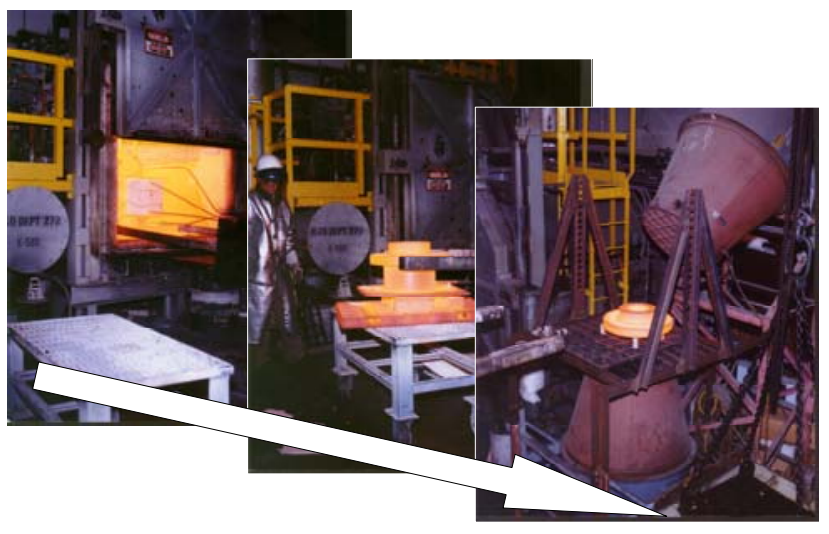

Figure 13. Dual heat-treat process sequence left to right. 1) Removal from furnace after solution, 2) Removal of heat treat fixture, and 3) Initiation of fan air quench. 
The initial DHT disk processing was completed without incident and produced a disk suitable for evaluation. The process met all temperature tolerance bands, as shown in Figure 14, and crack-free quenching was successfully completed. The post quench thermal cycles were also completed without incident.

Based on observations made during the initial René 104 DHT trial, recommendations were made to refine the process. These recommendations included improving the data logging and thermocouple capability, minor revisions in forging handling, and refinement of the control strategy to codify actions taken to maintain the process within the defined temperature tolerance bands. All of these revisions were included in the processing of the subsequent disks.

The thermal data are summarized in Figure 14, which indicate acceptable tolerances were achieved. Total furnace time during the solution cycle ranged from 76-90 minutes with bore cavity temperatures from $1109-1120^{\circ} \mathrm{C}$ $\left(10^{\circ} \mathrm{C}\right.$ range $)$ and rim metal temperatures from 1193 $1201^{\circ} \mathrm{C}\left(8^{\circ} \mathrm{C}\right.$ range $)$.

\begin{tabular}{|c|c|c|c|c|c|}
\hline Value & Adj Time & DHT bore1 & DHT bore2 & DHT rim1 & DHT rim2 \\
\hline \multirow{5}{*}{$\begin{array}{l}\text { Minimum } \\
\text { Maximum } \\
\text { Average }\end{array}$} & \multicolumn{5}{|c|}{ DHT Run \#1 } \\
\hline & 0 & 1109 & & 1199 & \\
\hline & 85 & 1116 & & 1201 & \\
\hline & & 1113 & & 1201 & \\
\hline & \multicolumn{5}{|c|}{ DHT Run \#2 } \\
\hline Minimum & 0 & 1110 & 1111 & 1196 & 1198 \\
\hline Maximum & 76 & 1116 & 1116 & 1199 & 1200 \\
\hline \multirow[t]{2}{*}{ Average } & & 1114 & 1115 & 1198 & 1200 \\
\hline & \multicolumn{5}{|c|}{ DHT Run \#3 } \\
\hline Minimum & 0 & 1114 & 1109 & 1193 & 1195 \\
\hline Maximum & 90 & 1120 & 1116 & 1199 & 1197 \\
\hline \multirow[t]{2}{*}{ Average } & & 1116 & 1111 & 1197 & 1196 \\
\hline & \multicolumn{5}{|c|}{ DHT Run \#4 } \\
\hline Minimum & 0 & 1115 & 1109 & 1198 & 1197 \\
\hline Maximum & 85 & 1117 & 1112 & 1200 & 1199 \\
\hline \multirow[t]{2}{*}{ Average } & & 1116 & 1111 & 1199 & 1198 \\
\hline & \multicolumn{5}{|c|}{ Overall } \\
\hline & & & ore & $\mathrm{Ri}$ & $\mathrm{m}$ \\
\hline Minimum & 76 & & 09 & 11 & 93 \\
\hline Maximum & 90 & & 20 & 12 & 01 \\
\hline
\end{tabular}

Figure 14. Thermal data from all dual heat-treat demonstration trials used to manufacture René 104 disks for evaluation indicating a consistent process was achieved.

Plots of only the solution portion of the cycle for bore and rim are shown with increasing detail in Figure 15. All confirm a consistent process was achieved from a thermal perspective.
Summary Of DHT Thermal Data

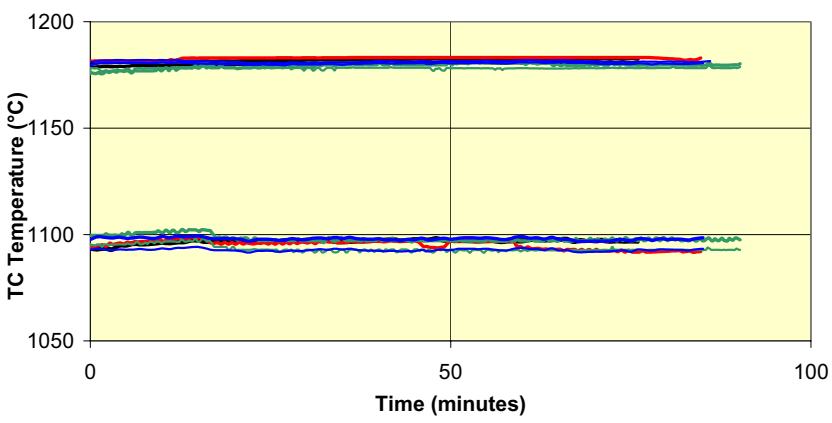

Figure 15. Thermal data during the solution cycle for both bore (lower data) and rim (upper data) thermocouples evaluation indicating a consistent process was achieved.

\section{Evaluation of DHT Forgings}

The initial disk was macro-etched with the grain size transition zone evident but difficult to capture photographically as shown in Figure 16. A radial slice was removed and macro etched with similar difficulties in highlighting the transition zone as shown in Figure 17. No surface non-uniformities or abnormal grain growth were observed in any surface or section evaluated.

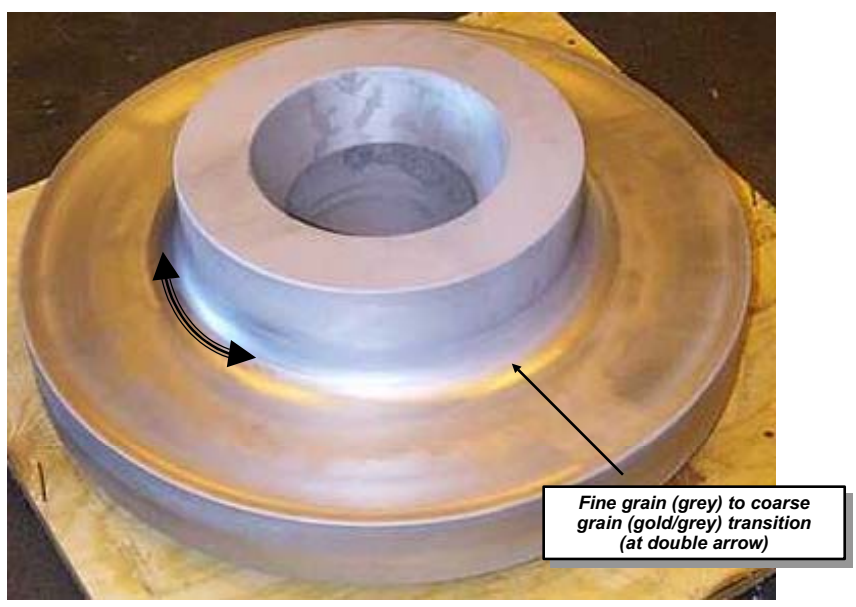

Figure 16. René 104 dual heat-treated disk in the macro-etched condition. The arrows and gold to gray color change identify the grain size transition zone location. 


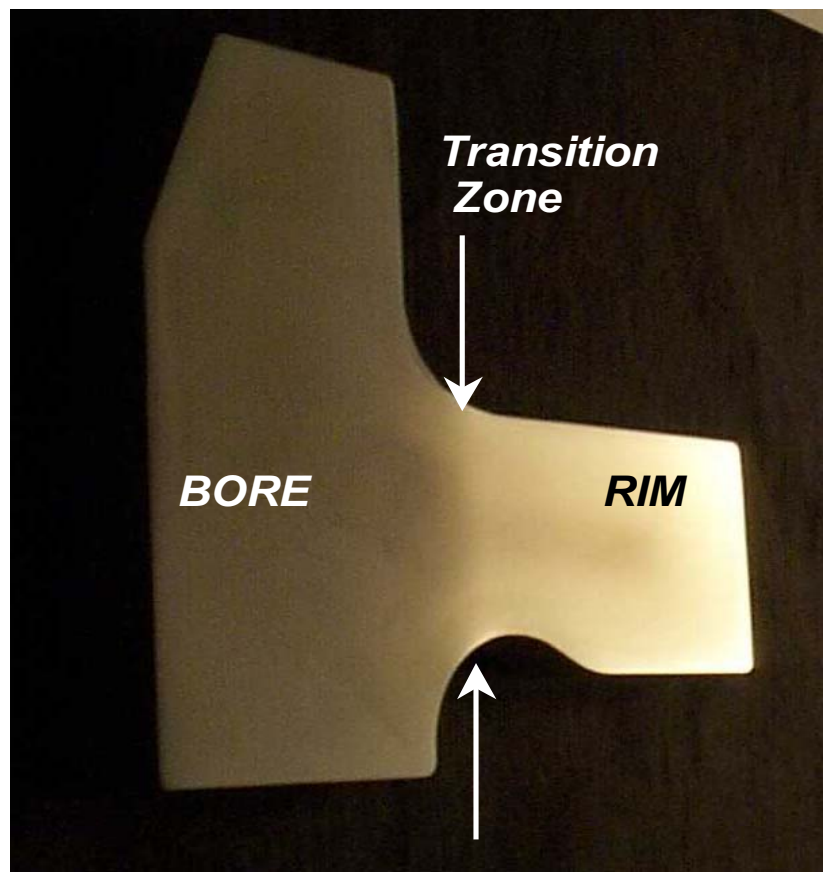

Figure 17. View of a radial cross section first René 104 DHT disk in the macro-etched condition. The arrows and gold to brown color transition note the grain size transition zone.

Quantitative grain size measurements were made on the cross-section to verify the grain size transition using Kallings etch and optical microscopy. This analysis revealed the transition zone to occur across a radial length of $6.4 \mathrm{~mm}$ as shown in Figure 18. A complete crosssection map of measured grain sizes is shown in Figure 19.

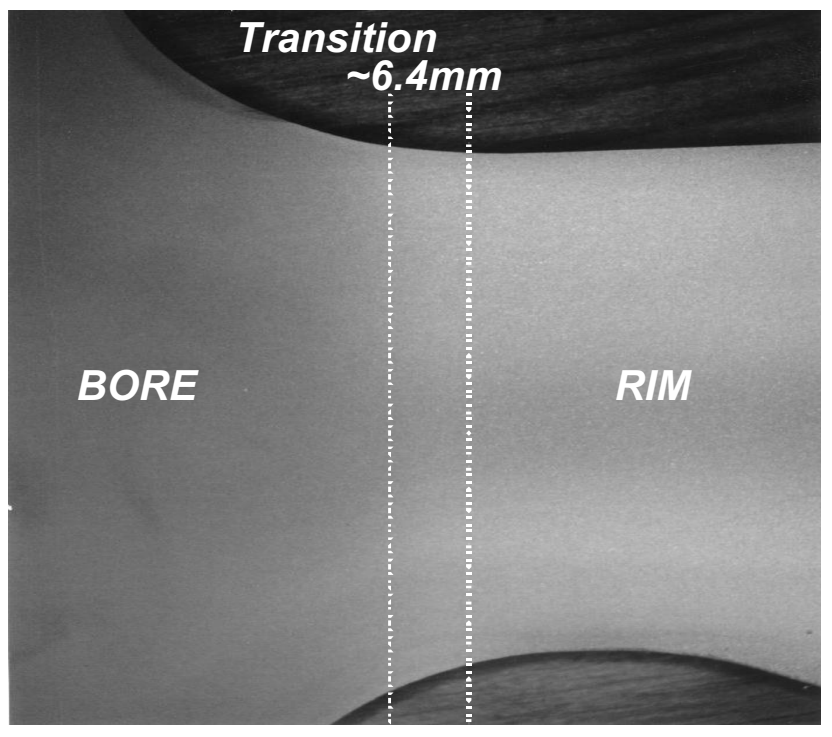

Figure 18. Micrograph of grain size transition region in first René 104 dual heat treat disk. Transition zone is highlighted by dotted lines.

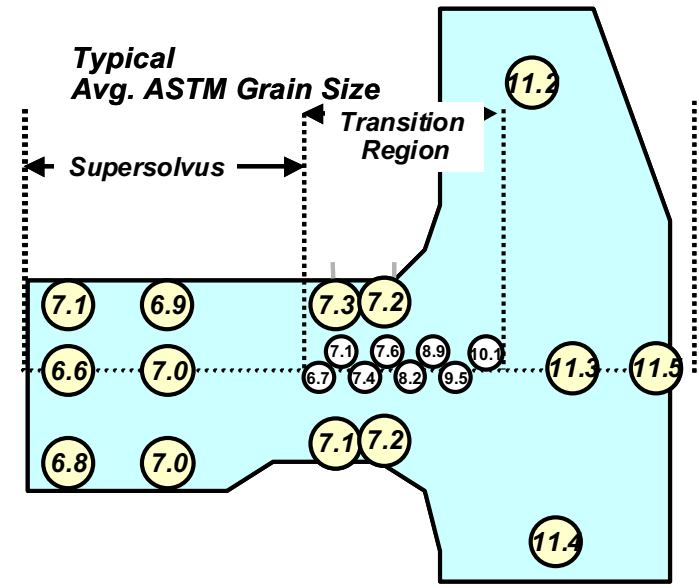

Figure 19. Schematic of the advanced disk shape crosssection with quantitative grain size measurements superimposed. Grain size appears uniform for both disks evaluated.

The rim grain size was confirmed to meet the target grain size and a uniform rim/web supersolvus grain size was observed with no radial or through the thickness variation. Furthermore, no thermally induced porosity, incipient melting, or signs of rim overheating were observed. The average grain size transitioned from ASTM 7 in the rim OD to ASTM 11.5 in the bore ID. The measured grain sizes met the program goals.

Further evaluations of other locations in three of the four DHT disks are shown in indicating minimal disk-to-disk grain size variability.

\section{DHT Disk Grain Size Profile}

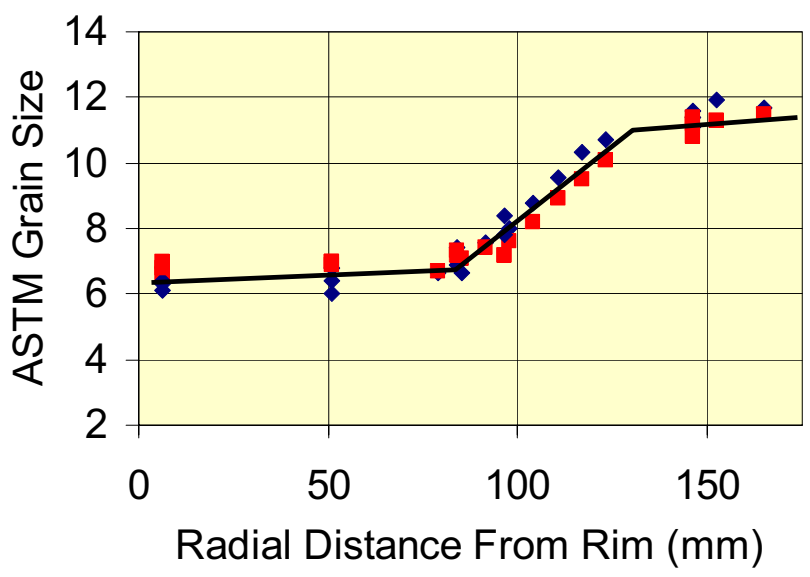

Figure 20. Grain size versus location including data from all three DHT disks evaluated. Different symbols indicate measurements from different DHT disks. 


\section{Non-destructive Evaluation (NDE) of Grain Structure}

The need for a NDE technique to assess transition zone placement has been identified as a critical item on the implementation plan for DHT technology. A crosssectional surface of the macro-slice from the initial DHT disk was inspected using a water-coupled acoustic microscope. The resulting image of the transition zone is shown in Figure 21. Transition zone contour and location are consistent with optical microscope measurements made on the same surface. Acoustic microscopy is clearly useful for the efficient evaluation of transition location and relative grain size for a macro-slice of DHT material. The potential for applying this NDE technique or others in a production environment appear feasible with further efforts.

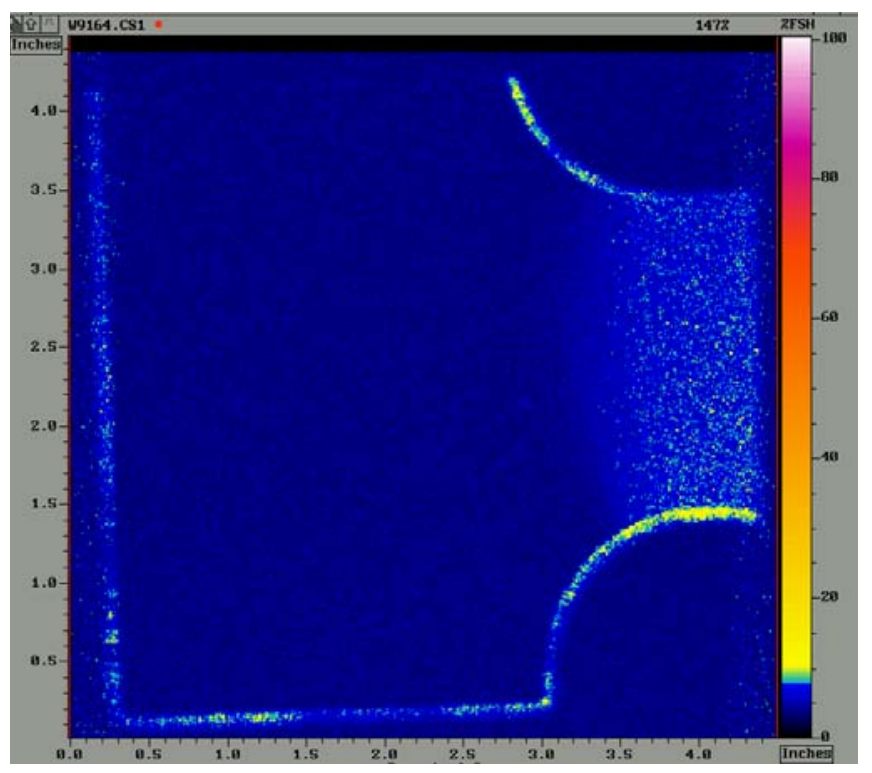

Figure 21. Acoustic microscope image of DHT transition zone cross-section.

\section{Summary of Activities and Accomplishments}

Nearly forty trials were performed to establish a preferred DHT practice. Trials included using thermo-coupled disk shapes to quantify the effects of cooling airflow and furnace modifications to provide a uniform disk temperature distribution. The thermocouple disk data was also used to establish a control strategy and to identify the preferred post DHT quench practice used on all full-scale demonstration disks. Finite element modeling of the DHT process was extensive and included over forty modeling runs.

The DHT thermal data from the full-scale trials indicates tight thermal tolerances were achieved. Total furnace time during the solution cycle ranged from 76-90 minutes with bore cavity temperatures varying less than $11^{\circ} \mathrm{C}$ and rim metal temperatures also varying less than $11^{\circ} \mathrm{C}$.

Excellent grain size uniformity was demonstrated via destructive evaluation of three disk shapes representing two heats of material. No evidence of abnormal grain growth or duplex grain structures was observed on disks heat treated per the defined practice.

Based on shape similarity, the developed process is ready for production application and should be readily adaptable to a variety of advanced military fighter type disk shapes. The process should be considered for development for large commercial engines.

\section{Acknowledgements}

The authors acknowledge the assistance of Ronald Tolbert at GE Aircraft Engines and Ron Wallis, Bill Konkel, MC Sharatchandra, and Ian Dempster at Wyman Gordon-PCC toward the successful development and demonstration on DHT technology. The authors also acknowledge the financial assistance of GE Aircraft Engines and the US Navy via the Dual Use Science and Technology Initiative as well as the technical support of Drs. Gil London and Stephen Fishman.

\section{References}

1. U. S. Patent $5,527,020$, June 18,1996

2. U. S. Patent $5,527,402$ June 18,1996

3. Government contract NAS3-26385

4. J.G. Groh et al "Alternative Material for Elevated Temperature Turbine Cooling Plate Applications" Superalloys 2004, Warrendale, PA, TMS, 2004.

5. European Patent Application EP1 195446 A1, "Ni Base Superalloy and It's Use in Gas Turbine Disks, Shafts, and Impellers", D.P. Mourer, K.R. Bain, P.L. Reynolds, J.J. Shirra, T.P. Gabb, 4/10/2000.

6. G.E. Maurer, W. Castledyne, F.A. Schweitzer, and S. Mancuso, "Development of HIP Consolidated P/M Superalloys for Conventional Forging to Gas Turbine Engine Components", Superalloys 1992, pp 645652, Warrendale, PA, TMS, 1992. 
